\title{
Risk Adjustment of the Credit-Card Augmented Divisia Monetary Aggregates
}

\author{
William A. Barnett \\ University of Kansas, Lawrence, and Center for Financial Stability, NY City \\ Liting $\mathrm{Su}$ \\ University of Kansas, Lawrence, and Center for Financial Stability, NY City
}

August 27, 2016

\begin{abstract}
While credit cards provide transactions services, as do currency and demand deposits, credit cards have never been included in measures of the money supply. The reason is accounting conventions, which do not permit adding liabilities, such as credit card balances, to assets, such as money. However, economic aggregation theory and index number theory measure service flows and are based on microeconomic theory, not accounting. Barnett, Chauvet, Leiva-Leon, and Su (2016) derived the aggregation and index number theory needed to measure the joint services of credit cards and money. They derived and applied the theory under the assumption of risk neutrality. But since credit card interest rates are high and volatile, risk aversion may not be negligible. We extend the theory by removing the assumption of risk neutrality to permit risk aversion in the decision of the representative consumer.
\end{abstract}

Keywords: Credit Cards, Money, Credit, Aggregation, Monetary Aggregation, Index Number Theory, Divisia Index, Risk, Euler Equations, Asset Pricing.

JEL Classification: C43, C53, C58, E01, E3, E40, E41, E51, E52, E58, G17.

\section{Introduction}

While money is an asset, credit is a liability. In accounting conventions, assets and liabilities cannot be added together. But aggregation theory and economic index number theory are based on microeconomic theory, not accounting conventions. Economic aggregates measure service flows. To the degree that money and some forms of credit produce joint services, those services can be aggregated.

A particularly conspicuous example is credit card services, which are directly involved in transactions and contribute to the economy's liquidity in ways not dissimilar to those of money. While money is both an asset and part of wealth, credit cards are neither. Hence credit cards are not money. To the degree that monetary policy operates through a wealth effect (Pigou effect), as advocated by Milton Friedman, credit cards do not play a role. But to the degree that the flow of monetary services is relevant to the economy, as through the demand for monetary 
services or as an indicator measure, the omission of credit card services from "money" measures induces a loss of information.

Barnett, Chauvet, Leiva-Leon, and Su (2016) derived the aggregation and index number theory needed to aggregate jointly over the services of money and credit cards. The derivation uses strongly simplifying assumptions. They assume credit cards are used to purchase consumer goods. All purchases are made at the beginning of periods, and payments for purchases are either by credit cards or money. Credit card purchases are repaid to the credit card company at the end of the current period or at the end of a future period, plus interest charged by the credit card company. Stated more formally, all discrete time periods are closed on the left and open on the right. After aggregation over consumers, the expected interest rate paid by the representative credit card holder can be very high, despite the fact that some consumers pay no interest on credit card balances.

The derivation in Barnett, Chauvet, Leiva-Leon, and Su (2016) assumes perfect certainty or risk neutrality. With monetary assets, having relatively low risk returns, risk aversion is not likely to have much effect on the behavior of aggregation theoretic monetary aggregates, such as the Divisia monetary aggregates. Studies have tended to show that weakening the assumption of risk neutrality in the derivation of the Divisia monetary aggregates has little effect on the behavior of the aggregates. See, e.g., Barnett, Liu, and Jensen (1997). But inclusion of credit card services introduces a high risk rate of return: the interest rate on credit card debt. As a result, extension of the aggregation theory to the case of risk neutrality might alter the behavior of the aggregate in a non-negligible manner. We extend the theory of Barnett, Chauvet, Leiva-Leon, and Su (2016) by removing the assumption of risk neutrality. The derivation is thereby altered by replacing the perfect certainty first order conditions with the relevant Euler equations.

To reflect the fact that money and credit cards provide services, such as liquidity and transactions services, money and credit are entered into a derived utility 
function, in accordance with Arrow and Hahn's (1971) proof. ${ }^{1}$ The derived utility function absorbs constraints reflecting the explicit motives for using money and credit card services. Since this paper is about measurement, we need only assume the existence of such motives. In the context of this research, we have no need to work backwards to reveal the explicit motives. As has been shown repeatedly, any of those motives, including the highly relevant transactions motive, are consistent with existence of a derived utility function absorbing the motive. ${ }^{2}$

\section{Intertemporal Allocation}

We begin by defining the variables in the risk neutral case for the representative consumer:

$$
\begin{aligned}
\mathbf{x}_{s}= & \text { vector of per capita (planned) consumptions of } N \text { goods and services } \\
& \text { (including those of durables) during period } s . \\
\mathbf{p}_{s}= & \text { vector of goods and services expected prices, and of durable goods } \\
& \text { expected rental prices during period } s . \\
m_{i s}= & \text { planned per capita real balances of monetary asset } i \text { during } \\
& \text { period } s(i=1,2, \ldots, n) .
\end{aligned}
$$

\footnotetext{
${ }^{1}$ Our research in this paper is not dependent upon the simple decision problem we use for derivation and illustration. In the case of monetary aggregation, Barnett (1987) proved that the same aggregator functions and index numbers apply, regardless of whether the initial model has money in the utility function or production function, so long as there is intertemporal separability of structure and separability of components over which aggregation occurs. That result is equally as applicable to our current results with augmented aggregation over monetary asset and credit card services. While this paper uses economic index number theory, it should be observed that there also exists a statistical approach to index number theory. That approach produces the same results, with the Divisia index interpreted to be the Divisia mean using expenditure shares as probability. See Barnett and Serletis (1990).

2 The aggregator function is the derived function that always exists, if monetary and credit card services have positive value in equilibrium. See, e.g., Samuelson (1948), Arrow and Hahn (1971), stockFischer (1974), Phlips and Spinnewyn (1982), Quirk and Saposnik (1968), and Poterba and Rotemberg (1987). Analogously, Feenstra (1986, p. 271) demonstrated "a functional equivalence between using real balances as an argument of the utility function and entering money into liquidity costs which appear in the budget constraints." The converse mapping from money and credit in the utility function back to the explicit motive is not unique. But in this paper we are not seeking to identify the explicit motives for holding money or credit card balances.
} 
$c_{j s}=$ planned per capita real expenditure with credit card type $j$ for transactions during period $s(j=1,2, \ldots, k)$. In the jargon of the credit card industry, those contemporaneous expenditures are called "volumes."

$z_{j s}=$ planned per capita rotating real balances in credit card type $j$ during period $s$ from transactions in previous periods $(j=1,2, \ldots, k)$. $y_{j s}=c_{j s}+z_{j s}=$ planned per capita total balances in credit type $j$ during period $s$ $(j=1,2, \ldots, k)$.

$r_{i s}=$ expected nominal holding period yield (including capital gains and losses) on monetary asset $i$ during period $s(i=1,2, \ldots, n)$.

$e_{j s}=$ expected interest rate on $c_{j s}$.

$\bar{e}_{j s}=$ expected interest rate on $z_{j s}$.

$A_{s}=$ planned per capita real holdings of the benchmark asset during period $s$. $R_{S}=$ expected (one-period holding) yield on the benchmark asset during period $s$. $L_{s}=$ per capita labor supply during period $s$. $w_{s}=$ expected wage rate during period $s$. $p_{s}^{*}=p_{s}^{*}\left(\mathbf{p}_{s}\right)$ is the true cost of living index, as defined in Barnett $(1978,1980)$.

The benchmark asset is defined to provide no services other than its expected yield, $R_{S}$, which motivates holding of the asset solely as a means of accumulating wealth. As a result, $R_{S}$ is the maximum expected holding period yield available to consumers in the economy in period $s$ from holding a secured asset. The benchmark asset is held to transfer wealth by consumers between multiperiod planning horizons, rather than to provide liquidity or other services. In contrast, $\bar{e}_{j s}$ is not the interest rate on an asset and is not secured. It is the interest rate on an unsecured liability, subject to substantial default and fraud risk. Hence, $\bar{e}_{j s}$ can be higher than the benchmark asset rate, and historically has always been much higher than the benchmark asset rate. ${ }^{3}$

\footnotetext{
${ }^{3}$ Barnett, Chauvet, Leiva-Leon, and Su (2016) follow the Center for Financial Stability (CFS) and the Bank of Israel in using the short term bank loan rate as a proxy for the benchmark rate. That interest
} 
It is important to recognize that the decision problem we model is not of a single economic agent, but rather of the "representative consumer," aggregated over all consumers. All quantities are therefore averaged over all consumers. Gorman's assumptions for the existence of a representative consumer are implicitly accepted, as is common in almost all modern macroeconomic theory having microeconomic foundations. This modeling assumption is particularly important in understand the credit card quantities and interest rates used in our research. About $20 \%$ of credit card holders in the United States do not pay explicit interest on credit card balances, since those credit card transactions are paid off by the end of the period. But the $80 \%$ who do pay interest pay very high interest rates. ${ }^{4}$ The Federal Reserve provides two interest rate series for credit card debt. One, $\bar{e}_{j s}$, includes interest only on accounts that do pay interest to the credit card issuing banks, while the other series, $e_{j s}$, includes the approximately $20 \%$ that do not pay interest. The latter interest rate is thereby lower, since it is averaged over interest paid on both categories of accounts. Since we are modeling the representative consumer, aggregated over all consumers, $e_{j s}$ is always less than $\bar{e}_{j s}$ for all $\mathrm{j}$ and s. The interest rate on rotating credit card balances, $\bar{e}_{j s}$, is paid by all consumers who maintain rotating balances in credit cards. But $e_{j s}$ is averaged over those consumers who maintain such rotating balances and hence pay interest on contemporaneous credit card transactions (volumes) and those consumers who pay off such credit card transactions before the end of the period, and hence do not pay explicit interest on the credit card transactions. The Federal Reserve provides data on both $\bar{e}_{j s}$ and $e_{j s}$.

rate has always exceeded the interest rate paid by banks on deposit accounts and on all other monetary assets used in the CFS Divisia monetary aggregates, and has always been lower than the Federal Reserve's reported average interest rate charged on credit card balances. For detailed information on CFS data sources, see Barnett, Liu, Mattson, and Noort (2013). For the additional data sources used by the CFS to extend to credit card services, see Barnett and Su (2016).

4 The following statement is from www.motherjones.com/kevin-drum/2011/10/americans-areclueless-about-their-credit-card-debt. "In the four working age categories, about $50 \%$ of households think they have outstanding credit card debt, but the credit card companies themselves think about $80 \%$ of households have outstanding balances." Since these percentages are of total households, including those having no credit cards, the percent of credit card holders paying interest might be even higher. 
Although $e_{j s}$ is less than $\bar{e}_{j s}, e_{j s}$ also has always been higher than the benchmark rate. This observation is a reflection of the so-called credit card debt puzzle. ${ }^{5}$

Barnett, Chauvet, Leiva-Leon, and Su (2016) use the latter interest rate, $e_{j s}$, in their augmented Divisia monetary aggregates formula, since the contemporaneous per capita transactions volumes in our model are averaged over both categories of credit card holders. They do not include rotating balances used for transactions in prior periods, since to do so would involve double counting of transactions services.

The expected interest rate, $e_{j s}$, can be explicit or implicit, and applies to the aggregated representative consumer. For example, an implicit part of that interest rate could be in the form of an increased price of the goods purchased or in the form of a periodic service fee or membership fee. But we use only the Federal Reserve's average explicit interest rate series, which is lower than the one that would include implicit interest. Nevertheless, that downward biased explicit rate of return to credit card companies, $e_{j s}$, aggregated over consumers, tends to be very high, far exceeding $R_{S}$, even after substantial losses from fraud.

We follow Barnett, Chauvet, Leiva-Leon, and Su (2016) in using the credit card industry's definition of "credit card," which excludes "store cards" and "charge cards." According to the trade's definition, "store cards" are issued by businesses providing credit only for their own goods, such as gasoline company credit cards or department store cards. To be a "credit card" by the trade's definition, the card must be widely accepted for many goods and services in the economy not constrained to cash-only sales. "Charge cards" can be widely accepted for goods purchases, but do not charge interest, since the debt must be paid off by the end of the period. To be a "credit card," the card must provide a line of credit to the card holder with interest charged on purchases not paid off by the end of the period. For example, American Express provides both charge cards and credit cards. The first credit card was provided by Bank of America. There now are four sources of credit

\footnotetext{
${ }^{5}$ See, e.g., Telyukova and Wright (2008), who view the puzzle as a special case of the rate dominance puzzle in monetary economics. The "credit card debt puzzle" asks why people do not pay down debt, when receiving low interest rates on deposits, while simultaneously paying higher interest rates on credit card debt.
} 
card services in the United States: Visa, Mastercard, Discover, and American Express. From American Express, we use only their credit card account services, not their charge cards. We use data from only those four sources, in accordance with the credit card industry's conventional definition of "credit card."

The resulting flow of funds identity for each period $s$ is:

$$
\begin{aligned}
\mathbf{p}_{s}^{\prime} \mathbf{x}_{s}=w_{s} L_{s}+ & \sum_{i=1}^{n}\left[\left(1+r_{i, s-1}\right) p_{s-1}^{*} m_{i, s-1}-p_{s}^{*} m_{i s}\right] \\
& +\sum_{j=1}^{k}\left[p_{s}^{*} c_{j s}-\left(1+e_{j, s-1}\right) p_{s-1}^{*} c_{j, s-1}\right] \\
& +\sum_{j=1}^{k}\left[p_{s}^{*} z_{j s}-\left(1+\bar{e}_{j, s-1}\right) p_{s-1}^{*} z_{j, s-1}\right]+\left[\left(1+R_{s-1}\right) p_{s-1}^{*} A_{s-1}\right. \\
& \left.-p_{s}^{*} A_{s}\right] .
\end{aligned}
$$

Planned per capita total balances in credit type $j$ during period $s$ are then $y_{j s}=c_{j s}+$ $z_{j s}$.

Equation (1) is an accounting identity, with the right hand side being funds available to purchase consumer goods during period $s$. On the right hand side, the first term is labor income. The second term is funds absorbed or released by rolling over the monetary assets portfolio, as explained in Barnett (1980). The third term is particularly important to this paper. That term is the net change in credit card debt during period $s$ from purchases of consumer goods, while the fourth term is the net change in rotating credit card debt. The fifth term is funds absorbed or released by rolling over the stock of the benchmark asset, as explained in Barnett (1980). The third term on the right side is specific to current period credit card purchases, while the fourth term is not relevant to the rest of our results, since $z_{j s}$ is not in the utility function. Hence $z_{j s}$ is not relevant to the user cost prices, conditional decisions, or aggregates in the rest of this paper. 
In the perfect certainty case, Barnett (1980) found that the current nominal user cost price, $\pi_{i t}$, of $m_{i t}$ is

$$
\pi_{i t}=\frac{p_{t}^{*}\left(R_{t}-r_{i t}\right)}{1+R_{t}}
$$

while Barnett, Chauvet, Leiva-Leon, and Su (2016) proved that the current period nominal user cost, $\tilde{\pi}_{j t}$, of $c_{j t}$ is

$$
\tilde{\pi}_{j t}=\frac{p_{t}^{*}\left(e_{j t}-R_{t}\right)}{1+R_{t}}
$$

The corresponding real user costs are

$$
\pi_{j s}^{*}=\frac{\pi_{i s}}{p_{s}^{*}}
$$

and

$$
\tilde{\pi}_{j s}^{*}=\frac{\tilde{\pi}_{j t}}{p_{s}^{*}}
$$

Equation (3) can be understood in terms of the delay between the goods purchase date and the date of repayment of the loan to the credit card company. During the one period delay, the consumer can invest the cost of the goods purchased at rate of return $R_{t}$. Hence the net real cost to the consumer of the credit card loan, per dollar borrowed, is $e_{j t}-R_{t}$. Multiplication by the true cost of living index in the numerator of (3) converts to nominal dollars and division by $1+R_{t}$ discounts to present value within the time period.

\section{Risk Adjustment}


In index number theory, it is known that uncertainty about future variables has no effect on contemporaneous aggregates or index numbers, if preferences are intertemporally separable. Only contemporaneous risk is relevant. See, e.g., Barnett (1995). Prior to Barnett, Liu, and Jensen (1997)), the literature on index number theory assumed that contemporaneous prices are known with certainty, as is reasonable for consumer goods. But Poterba and Rotemberg (1987) observed that contemporaneous user cost prices of monetary assets are not known with certainty, since interest rates are not paid in advance. As a result, the need existed to extend the field of index number theory to the case of contemporaneous risk.

For example, the derivation of the Divisia monetary index in Barnett (1980) uses the perfect certainty first-order conditions for expenditure constrained maximization of utility, in a manner similar to Francois Divisia's $(1925,1926)$ derivation of the Divisia index for consumer goods. But if the contemporaneous user costs are not known with certainty, those first order conditions become Euler equations. This observation motivated Barnett, Liu, and Jensen (1997)) to repeat the steps in the Barnett (1980) with the first order conditions replaced by Euler equations. In this section, we analogously derive an extended augmented Divisia index using the Euler equations that apply under risk, with utility assumed to be intertemporally strongly separable. The result is a Divisia index with the user costs adjusted for risk in a manner consistent with the CCAPM (consumption capital asset price model). 6

The approach to our derivation of the extended index closely parallels that in Barnett, Liu, and Jensen (1997), Barnett and Serletis (2000, ch. 12), and Barnett (2012, Appendix D) for monetary assets alone. But our results, including credit card services, are likely to result in substantially higher risk adjustments than the earlier results for monetary assets alone, since interest rates on credit card debt are much higher and much more volatile than on monetary assets.

\subsection{The Decision}

${ }^{6}$ Regarding CCAPM, see Lucas (1978), Breeden (1979), and Cochrane (2000). 
Define $Y$ to be the consumer's survival set, assumed to be compact. The decision problem in this section will differ from the one in Barnett, Chauvet, Leiva-Leon, and Su (2016) not only by introducing risk, but also by adopting an infinite planning horizon. The consumption possibility set, $S(s)$, for period $s$ is the set of survivable points, ( $\left.\mathbf{m}_{s}, \mathbf{c}_{s}, \mathbf{x}_{s}, A_{s}\right)$ satisfying equation (2).

The benchmark asset $A_{s}$ provides no services other than its yield, $R_{S}$. As a result, the benchmark asset does not enter the consumer's contemporaneous utility function. The asset is held only as a means of accumulating wealth. The consumer's subjective rate of time preference, $\xi$, is assumed to be constant. The single-period utility function, $u\left(\mathbf{m}_{t}, \mathbf{c}_{t}, \mathbf{x}_{t}\right)$, is assumed to be increasing and strictly quasi-concave.

The consumer's decision problem is the following.

Problem 1. Choose the deterministic point $\left(\mathbf{m}_{t}, \mathbf{c}_{t}, \mathbf{x}_{t}, A_{t}\right)$ and the stochastic process $\left(\mathbf{m}_{s}, \mathbf{c}_{s}, \mathbf{x}_{s}, A_{s}\right), s=t+1, \ldots, \infty$, to maximize

$$
u\left(\mathbf{m}_{t}, \mathbf{c}_{t}, \mathbf{x}_{t}\right)+E_{t}\left[\sum_{s=t+1}^{\infty}\left(\frac{1}{1+\xi}\right)^{s-t} u\left(\mathbf{m}_{s}, \mathbf{c}_{s}, \mathbf{x}_{s}\right)\right]
$$

subject to $\left(\mathbf{m}_{s}, \mathbf{c}_{s}, \mathbf{x}_{s}, A_{s}\right) \in S(s)$ for $s=t, \mathrm{t}+1, \ldots, \infty$, and also subject to the transversality condition

$$
\lim _{s \rightarrow \infty} E_{t}\left(\frac{1}{1+\xi}\right)^{s-t} A_{s}=0 .
$$

\subsection{Existence of an Augmented Monetary Aggregate for the Consumer}


We assume that the utility function, $u$, is blockwise weakly separable in $\left(\mathbf{m}_{s}, \mathbf{c}_{s}\right)$ and in $\boldsymbol{x}_{s} \cdot{ }^{7}$ Hence, there exists an augmented monetary aggregator function, $\mathcal{M}$, consumer goods aggregator function, $X$, and utility functions, $F$ and $H$, such that

$$
u\left(\mathbf{m}_{s}, \mathbf{c}_{s}, \mathbf{x}_{s}\right)=F\left[\mathcal{M}\left(\mathbf{m}_{s}, \mathbf{c}_{s}\right), X\left(\mathbf{x}_{s}\right)\right] .
$$

We define the utility function $V$ by $V\left(\mathbf{m}_{s}, \mathbf{c}_{s}, X_{s}\right)=F\left[\mathcal{M}\left(\mathbf{m}_{s}, \mathbf{c}_{s}\right), X_{s}\right]$, where aggregate consumption of goods is defined by $X_{s}=X\left(\boldsymbol{x}_{s}\right)$. It follows that the exact augmented monetary aggregate is

$$
\mathcal{M}{ }_{s}=\mathcal{M}\left(\mathbf{m}_{s}, \mathbf{c}_{s}\right) .
$$

The fact that blockwise weak separability is a necessary condition for exact aggregation is well known in the perfect-certainty case. If the resulting aggregator function also is linearly homogeneous, two-stage budgeting can be used to prove that the consumer behaves as if the exact aggregate were an elementary good. Although two-stage budgeting theory is not applicable under risk, $\mathcal{M}\left(\boldsymbol{m}_{s}, \boldsymbol{c}_{s}\right)$ remains the exact aggregation-theoretic quantity aggregate in a well-defined sense, even under risk. ${ }^{8}$

The Euler equations that will be of the most use to us below are those for monetary assets and credit card services. Those Euler equations are

$$
E_{S}\left[\frac{\partial V}{\partial m_{i s}}-\rho \frac{p_{s}^{*}\left(R_{s}-r_{i s}\right)}{p_{s+1}^{*}} \frac{\partial V}{\partial X_{S+1}}\right]=0
$$

and

\footnotetext{
${ }^{7} \mathrm{~A}$ long literature exists on testing the important assumption of blockwise weak separability of preferences. Recent contributions include Cherchye, Demuynck, Rock, and Hjerstrand (2015) and Hjertstrand, Swofford, and Whitney (2016). ${ }^{8}$ See Barnett (1995) and the appendix in Barnett, Liu, and Jensen (1997).
} 


$$
E_{S}\left[\frac{\partial V}{\partial c_{j s}}-\rho \frac{p_{s}^{*}\left(e_{j s}-R_{S}\right)}{p_{s+1}^{*}} \frac{\partial V}{\partial X_{s+1}}\right]=0
$$

for all $s \geq t, i=1, \ldots, n$, and $j=1, \ldots, k$, where $\rho=1 /(1+\xi)$ and where $p_{s}^{*}$ is the exact price aggregate that is dual to the consumer goods quantity aggregate $X_{S}$.

Similarly, we can acquire the Euler equation for the consumer goods aggregate, $X_{S}$, rather than for each of its components. The resulting Euler equation for $X_{S}$ is

$$
E_{S}\left[\frac{\partial V}{\partial X_{s}}-\rho \frac{p_{s}^{*}\left(1+R_{S}\right)}{p_{s+1}^{*}} \frac{\partial V}{\partial X_{S+1}}\right]=0 .
$$

For the two available approaches to derivation of the Euler equations, see the Appendix.

\subsection{The Perfect-Certainty Case}

In the perfect-certainty case with finite planning horizon, we have already shown in section 2 that the contemporaneous nominal user cost of the services of $m_{i t}$ is equation (2) and the contemporaneous nominal user cost of credit card services is equation (3). We have also shown in Barnett, Chauvet, Leiva-Leon, and $\mathrm{Su}(2016)$ that the solution value of the exact monetary aggregate, $\mathcal{M}\left(\mathbf{m}_{t}, \mathbf{c}_{t}\right)=$ $\mathcal{M}\left(\mathbf{m}_{\mathrm{t}}^{\mathrm{a}}\right)$, can be tracked without error in continuous time by the Divisia index.

The flawless tracking ability of the index in the perfect-certainty case holds regardless of the form of the unknown aggregator function, $\mathcal{M}$. Aggregation results derived with finite planning horizon also hold in the limit with infinite planning horizon. See Barnett (1987, section 2.2). Hence those results continue to apply. However, under risk, the ability of the Divisia index to track $\mathcal{M}\left(\mathbf{m}_{t}, \mathbf{c}_{t}\right)$ is compromised.

\subsection{New Generalized Augmented Divisia Index}

\subsubsection{User Cost Under Risk Aversion}


We now find the formula for the user costs of monetary services and credit card services under risk.

Definition 1. The contemporaneous risk-adjusted real user cost price of the services of $m_{i t}^{a}$ is $p_{i t}^{a}$, defined such that

$$
p_{i t}^{a}=\frac{\frac{\partial V}{\partial m_{i t}^{a}}}{\frac{\partial V}{\partial X_{t}}}, i=1,2, \ldots, n+k
$$

The above definition for the contemporaneous user cost states that the real user cost price of an augmented monetary asset is the marginal rate of substitution between that asset and consumer goods.

For notational convenience, we convert the nominal rates of return, $r_{i t}, e_{j t}$ and $R_{t}$, to real total rates, $1+r_{i t}^{*}, 1+e_{j t}^{*}$ and $1+R_{t}^{*}$ such that

$$
\begin{aligned}
& 1+r_{i t}^{*}=\frac{p_{t}^{*}\left(1+r_{i t}\right)}{p_{t+1}^{*}}, \\
& 1+e_{j t}^{*}=\frac{p_{t}^{*}\left(1+e_{j t}\right)}{p_{t+1}^{*}}, \\
& 1+R_{t}^{*}=\frac{p_{t}^{*}\left(1+R_{t}\right)}{p_{t+1}^{*}},
\end{aligned}
$$

where $r_{i t}^{*}, e_{j t}^{*}$, and $R_{t}^{*}$ are called the real rates of excess return. Under this change of variables and observing that current-period marginal utilities are known with certainty, Euler equations (9a), (9b), and (9c) become

$$
\frac{\partial V}{\partial m_{i t}}-\rho E_{t}\left[\left(R_{t}^{*}-r_{i t}^{*}\right) \frac{\partial V}{\partial X_{t+1}}\right]=0,
$$




$$
\frac{\partial V}{\partial c_{j t}}-\rho E_{t}\left[\left(e_{j t}^{*}-R_{t}^{*}\right) \frac{\partial V}{\partial X_{t+1}}\right]=0,
$$

and

$$
\frac{\partial V}{\partial X_{t}}-\rho E_{t}\left[\left(1+R_{t}^{*}\right) \frac{\partial V}{\partial X_{t+1}}\right]=0 .
$$

We now can provide our user cost theorem under risk.

Theorem 1 (a). The risk adjusted real user cost of the services of monetary asset $i$ under risk is $p_{i t}^{m}=\pi_{i t}+\psi_{i t}$, where

$$
\pi_{i t}=\frac{E_{t} R_{t}^{*}-E_{t} r_{i t}^{*}}{1+E_{t} R_{t}}
$$

and

$$
\psi_{i t}=\rho\left(1-\pi_{i t}\right) \frac{\operatorname{Cov}\left(R_{t}^{*}, \frac{\partial V}{\partial X_{t+1}}\right)}{\frac{\partial V}{\partial X_{t}}}-\rho \frac{\operatorname{Cov}\left(r_{i t}^{*}, \frac{\partial V}{\partial X_{t+1}}\right)}{\frac{\partial V}{\partial X_{t}}} .
$$

(b). The risk adjusted real user cost of the services of credit card type $j$ under risk is $p_{j t}^{c}=\tilde{\pi}_{j t}+\tilde{\psi}_{j t}$, where

$$
\tilde{\pi}_{j t}=\frac{E_{t} e_{j t}^{*}-E_{t} R_{t}^{*}}{1+E_{t} R_{t}}
$$

and 


$$
\tilde{\psi}_{j t}=\rho \frac{\operatorname{Cov}\left(e_{j t}^{*}, \frac{\partial V}{\partial X_{t+1}}\right)}{\frac{\partial V}{\partial X_{t}}}-\rho\left(1+\tilde{\pi}_{j t}\right) \frac{\operatorname{Cov}\left(R_{t}^{*}, \frac{\partial V}{\partial X_{t+1}}\right)}{\frac{\partial V}{\partial X_{t}}}
$$

Proof. See the Appendix.

Under risk neutrality, the covariances in (16) and (17) would all be zero, because the utility function would be linear in consumption. Hence, the user cost of monetary assets and credit card services would reduce to $\pi_{i, t}$ and $\tilde{\pi}_{j, t}$ respectively, as defined in equation (14) and (16). The following corollary is immediate.

Corollary 1 to Theorem 1. Under risk neutrality, the user cost formulas are the same as equation (2) and (3) in the perfect-certainty case, but with all interest rates replaced by their expectations.

\subsubsection{Generalized Augmented Divisia Index Under Risk Aversion}

In the case of risk aversion, the first-order conditions are Euler equations. We now use those Euler equations to derive a generalized Divisia index, as follows.

Theorem 2. In the share equations, $\omega_{i t}=\pi_{i t}^{a} m_{i t}^{a} / \boldsymbol{\pi}_{t}^{a \prime} \mathbf{m}_{t}^{a}$, we replace the user costs, $\boldsymbol{\pi}_{t}^{a}=\left(\boldsymbol{\pi}_{t}^{\prime}, \widetilde{\boldsymbol{\pi}}_{t}^{\prime}\right)^{\prime}$, defined by (2) and (3), by the risk-adjusted user costs, $p_{i t}^{a}$, defined by Definition 1, to produce the risk adjusted shares, $s_{i t}=p_{i t}^{a} m_{i t}^{a} / \sum_{j=1}^{n+k} p_{j t}^{a} m_{j t}^{a}$. Under our weak-separability assumption, $V\left(\mathbf{m}_{s}, \mathbf{c}_{s}, X_{S}\right)=F\left[\mathcal{M}\left(\mathbf{m}_{s}, \mathbf{c}_{s}\right), X_{S}\right]$, and our assumption that the monetary aggregator function, $\mathcal{M}$, is linearly homogeneous, the following generalized augmented Divisia index is true under risk:

$$
d \log \mathcal{M}_{t}=\sum_{i=1}^{n+k} s_{i t} d \log m_{i t}^{a}
$$

Proof. See the Appendix. 
The exact tracking of the Divisia monetary index is not compromised by risk aversion, as long as the adjusted user costs, $\pi_{i t}+\psi_{i t}$ and $\tilde{\pi}_{j t}+\tilde{\psi}_{j t}$, are used in computing the index. The adjusted user costs reduce to the usual user costs in the case of perfect certainty, and our generalized Divisia index (18) reduces to the usual Divisia index. Similarly, the risk-neutral case is acquired as the special case with $\psi_{i t}=\tilde{\psi}_{j t}=0$, so that equations (14) and (16) serve as the user costs. In short, our generalized augmented Divisia index (18) is a true generalization, in the sense that the risk-neutral and perfect-certainty cases are strictly nested special cases. Formally, that conclusion is the following.

Corollary 1 to Theorem 2. Under risk neutrality, the generalized Divisia index (18) reduces to the perfect certainty Divisia index in Barnett, Chauvet, Leiva-Leon, and Su (2016), where the user costs in the formula are defined by (14) and (16).

\subsection{CCAPM Special Case}

As a means of illustrating the nature of the risk adjustments, $\psi_{i, t}$ and $\tilde{\psi}_{j, t}$, we consider a special case, based on the usual assumptions in CAPM theory of either quadratic utility or Gaussian stochastic processes. Direct empirical use of Theorems 1 and 2, without any CAPM simplifications, would require availability of prior econometric estimates of the parameters of the utility function, $V$, and of the subjective rate of time discount. Under the usual CAPM assumptions, we show in this section that empirical use of Theorems 1 and 2 would require prior estimation of only one property of the utility function: the degree of risk aversion, on which a large body of published information is available.

Consider first the following case of utility that is quadratic in consumption of goods, conditionally on the level of monetary asset and credit card services.

Assumption 1. Let $V$ have the form 


$$
V\left(\mathbf{m}_{t}, \mathbf{c}_{t}, X_{t}\right)=F\left[\mathcal{M}\left(\mathbf{m}_{t}, \mathbf{c}_{t}\right), X_{t}\right]=A\left[\mathcal{M}\left(\mathbf{m}_{t}, \mathbf{c}_{t}\right)\right] X_{t}-\frac{1}{2} B\left[\mathcal{M}\left(\mathbf{m}_{t}, \mathbf{c}_{t}\right)\right] X_{t}^{2},
$$

where $A$ is a positive, increasing, concave function and $B$ is a nonnegative, decreasing, convex function.

The alternative assumption is Guassianity, as follows:

Assumption 2. Let $\left(r_{i t}^{*}, e_{j t}^{*}, X_{t+1}\right)$ be a trivariate Gaussian process for each asset $i=$ $1, \ldots, n$, and credit card service, $j=1, \ldots, k$.

We also make the following conventional CAPM assumption:

Assumption 3. The benchmark rate process is deterministic or already riskadjusted, so that $R_{t}^{*}$ is the risk-free rate.

Under this assumption, it follows that

$$
\operatorname{Cov}\left(R_{t}^{*}, \frac{\partial V}{\partial X_{t+1}}\right)=0
$$

We define $H_{t+1}=H\left(\mathcal{M}_{t+1}, X_{t+1}\right)$ to be the well-known Arrow-Pratt measure of absolute risk aversion,

$$
H\left(\mathcal{M}_{t+1}, X_{t+1}\right)=-\frac{E_{t}\left[V^{\prime \prime}\right]}{E_{t}\left[V^{\prime}\right]}
$$

where $V^{\prime}=\partial V\left(\mathbf{m}_{t+1}^{a}, X_{t+1}\right) / \partial X_{t+1}$ and $V^{\prime \prime}=\partial^{2} V\left(\mathbf{m}_{t+1}^{a}, X_{t+1}\right) / \partial X_{t+1}^{2}$. In this definition, risk aversion is measured relative to consumption risk, conditionally upon the level of augmented monetary services produced by $\mathcal{M} t_{t+1}=\mathcal{M}\left(\mathbf{m}_{t}, \mathbf{c}_{t}\right)$. 
Under risk aversion, $H_{t+1}$ is positive and increasing in the degree of absolute risk aversion. The following lemma is central to our Theorem 3.

Lemma 2. Under Assumption 3 and either Assumption 1 or Assumption 2, the usercost risk adjustments, $\psi_{i t}$ and $\tilde{\psi}_{j t}$, defined by (15) and (17), reduce to

$$
\psi_{i t}=\frac{1}{1+R_{t}^{*}} H_{t+1} \operatorname{cov}\left(r_{i t}^{*}, X_{t+1}\right)
$$

and

$$
\tilde{\psi}_{j t}=-\frac{1}{1+R_{t}^{*}} H_{t+1} \operatorname{cov}\left(e_{j t}^{*}, X_{t+1}\right)
$$

Proof. See the Appendix.

The following theorem identifies the effect of the risk adjustment on the expected own interest rates in the user cost formulas.

Theorem 3. Let $\hat{H}_{t}=H_{t+1} X_{t}$. Under the assumptions of Lemma 2, we have the following for each asset $i=1, \ldots, n$, and credit card service, $j=1, \ldots, k$.

$$
p_{i t}^{m}=\frac{E_{t} R_{t}^{*}-\left(E_{t} r_{i t}^{*}-\phi_{i t}\right)}{1+E_{t} R_{t}^{*}}
$$

where

$$
\phi_{i t}=\hat{H}_{t} \operatorname{Cov}\left(r_{i t}^{*}, \frac{X_{t+1}}{X_{t}}\right)
$$

and

$$
p_{j t}^{c}=\frac{\left(E_{t} e_{j t}^{*}-\tilde{\phi}_{j t}\right)-E_{t} R_{t}^{*}}{1+E_{t} R_{t}^{*}}
$$

where

$$
\tilde{\phi}_{j t}=\hat{H}_{t} \operatorname{Cov}\left(e_{j t}^{*}, \frac{X_{t+1}}{X_{t}}\right)
$$


Proof. See the Appendix.

As defined, $\hat{H}_{t}$ is a time shifted Arrow-Pratt relative risk aversion measure.

Theorem 3 shows that the risk adjustment on the own interest rate for a monetary asset or credit card service depends upon relative risk aversion, $\hat{H}_{t}$, and the covariance between the consumption growth path, $X_{t+1} / X_{t}$, and the real rate of excess return earned on a monetary asset, $r_{i t}^{*}$, or paid on a credit card service, $e_{j t}^{*}$.

\subsection{Magnitude of the Adjustment}

In accordance with the large and growing literature on the equity premium puzzle, the CCAPM risk adjustment term is widely believed to be biased downward. ${ }^{9}$ A promising explanation may be the customary assumption of intertemporal separability of utility, since response to a change in an interest rate may not be fully reflected in contemporaneous changes in consumption. Hence the contemporaneous covariance in the CCAPM "beta" correction may not take full account of the effect of an interest rate change on life style. An approach to risk adjustment without assumption of intertemporal separability was developed for monetary aggregation by Barnett and Wu (2005). We have not yet applied that more complicated approach to weaken our assumptions further. While we have removed the assumption of risk neutrality, we have assumed intertemporal separability in deriving the Euler equations on which our aggregation theory is based. In later research, we plan to apply the approach of Barnett and Wu (2005) to further weaken the assumptions by removing the assumptions of intertemporal separability.

\section{Conclusions}

${ }^{9}$ See, e.g., Campbell and Cochrane (1999), Cochrane (2000), Kocherlakota (1996), Marshall (1997), Mehra and Prescott (1985). 
Many economists have wondered how the transactions services of credit cards could be included in monetary aggregates. The conventional simple sum accounting approach precludes solving that problem, since accounting conventions do not permit adding liabilities to assets. But economic aggregation and index number theory measure service flows, independently of whether from assets or liabilities. Barnett, Chauvet, Leiva-Leon, and Su (2016) provided the theory solving that long overlooked problem, but under the assumption of risk neutrality. The Center for Financial Stability (CFS) is now providing the unaugmented aggregates, $M_{t}=M(\mathbf{m} t)$, and will soon be providing the credit-card-augmented aggregates $\mathcal{M}_{t}=\mathcal{M}\left(\mathbf{m}_{t}, \mathbf{c}_{t}\right)$, derived under the assumption of risk neutrality. The new aggregates will be provided to the public in monthly releases by the CFS and also to Bloomberg terminal users.

While excluding credit card services, the currently available CFS Divisia monetary aggregates have been found to be reasonably robust to introduction of risk, variations of the benchmark rate, introduction of taxation of interest rates, and other such refinements. ${ }^{10}$ But such simplifications might not be the case with the augmented monetary aggregates, because of the high and volatile interest rates on credit card balances. As a result, in this paper we have extended the theory to CCAPM risk adjustment under risk aversion. Empirical application of this theory remains a topic for future research.

An extensive literature exists on policy relevance of the Divisia monetary aggregates. See, e. g., Barnett (2012), Belongia and Ireland (2014; 2015a,b; 2016), Barnett and Chauvet (2011a,b), Serletis and Rahman (2013), and Serletis and Gogas (2014). Much of that literature could be strengthened further by use of the soon to be available credit-card augmented CFS Divisia monetary aggregates and perhaps further strengthened by removing the assumption of risk neutrality in accordance with the theory in this paper.

\footnotetext{
${ }^{10}$ While those refinements slightly change the un-augmented Divisia monetary aggregates, those changes are negligible relative to the gap between the simple sum monetary aggregate path and the corresponding Divisia monetary aggregate path. See, e.g., the online library of relevant research and the Divisia monetary aggregates databases at the Center for Financial Stability (www.centerforfinancialstability.org/amfm.php).
} 
A more demanding approach would remove the CCAPM assumption of intertemporal separability, in accordance with Barnett and Wu (2005). Adapting that advanced approach to our augmented aggregates, including credit card services, remains a topic for future research. 


\section{REFERENCES}

Arrow, K. J. and F. Hahn (1971). General Competitive Analysis. San Francisco, HoldenDay.

Barnett, W. A. (1978). "The User Cost of Money," Economics Letter 1: 145-149.

Reprinted in W. A. Barnett and A. Serletis (eds.), 2000, The Theory of Monetary Aggregation, North Holland, Amsterdam, chapter 1: 6-10.

Barnett, W. A. (1980). "Economic Monetary Aggregates: An Application of Aggregation and Index Number Theory," Journal of Econometrics 14: 11-48. Reprinted in W. A. Barnett and A. Serletis (eds.), 2000, The Theory of Monetary Aggregation, North Holland, Amsterdam, chapter 1: 6-10.

Barnett, W. A. (1987). "The Microeconomic Theory of Monetary Aggregation," in W. A. Barnett and K. Singleton (eds.), New Approaches to Monetary Economics, Cambridge U. Press. Reprinted in W. A. Barnett and A. Serletis (eds.), 2000, The Theory of Monetary Aggregation, North Holland, Amsterdam, chapter 3: 49-99.

Barnett, W.A. (1995). "Exact Aggregation under Risk," in W. A. Barnett, M. Salles, H. Moulin, and N. Schofield (eds.), Social Choice, Welfare and Ethics, Cambridge University Press, Cambridge. Reprinted in W. A. Barnett and A. Serletis, (eds.), 2000, The Theory of Monetary Aggregation, North Holland, Amsterdam, chapter 10: $195-216$.

Barnett, W. A. (2012). Getting It Wrong: How Faulty Monetary Statistics Undermine the Fed, the Financial System, and the Economy, MIT Press, Cambridge, MA.

Barnett, W.A. and M. Chauvet (2011a). "How Better Monetary Statistics Could Have Signaled the Financial Crisis". Journal of Econometrics 161(1): 6-23.

Barnett, W.A. and M. Chauvet (eds) (2011b). Financial Aggregation and Index Number Theory. Singapore: World Scientific.

Barnett, W. A. and A. Serletis (1990)." A Dispersion-Dependency Diagnostic Test for Aggregation Error: with Applications to Monetary Economics and Income Distribution," Journal of Econometrics 43: 5-34. Reprinted in W. A. Barnett and A. Serletis (eds.), 2000, The Theory of Monetary Aggregation, North-Holland, Amsterdam, chapter 9: 167-194

Barnett, W. A. and A. Serletis (eds) (2000). The Theory of Monetary Aggregation, Contributions to Economic Analysis Monograph Series, Elsevier, Amsterdam.

Barnett, W. A. and S. Wu (2005). "On User Costs of Risky Monetary Assets," Annals of Finance 1, 35-50. Reprinted in W. A. Barnett and M. Chauvet (eds.), 2010, 
Financial Aggregation and Index Number Theory, World Scientific, Singapore, chapter 3.

Barnett, W. A. and L. Su (2016). "Data Sources for the Credit-Card Augmented Divisia Monetary Aggregates," Research in International Business and Finance, Elsevier, forthcoming.

Barnett, W. A., M. Chauvet, D. Leiva-Leon, and L. Su (2016). "Nowcasting Nominal GDP with the Credit-Card Augmented Divisia Monetary Aggregates," Johns Hopkins University Studies in Applied Economics, SAE Working Paper No. 59.

Barnett, W. A., Y. Liu, and M. Jensen (1997). "The CAPM Risk Adjustment for Exact Aggregation over Financial Assets," Macroeconomic Dynamics 1: 485-

512.Reprinted in W. A. Barnett and A. Serletis (eds.), 2000, The Theory of Monetary Aggregation, North Holland, Amsterdam, chapter 12: 245-295.

Barnett, W.A., J. Liu, R.S. Mattson, and J. van den Noort (2013). "The New CFS Divisia Monetary Aggregates: Design, Construction, and Data Sources," Open Economies Review 24: 101-124.

Belongia, M.T. and P.N. Ireland (2014). "The Barnett Critique after Three Decades: A New Keynesian Analysis”. Journal of Econometrics 183(1): 5-21.

Belongia, M.T. and P.N. Ireland (2015a). "Interest Rates and Money in the Measurement of Monetary Policy." Journal of Business and Economic Statistics 332: 255-269.

Belongia, M.T. and P.N. Ireland (2015b). “A 'Working' Solution to the Question of Nominal GDP Targeting.”Macroeconomic Dynamics 19: 508-534.

Belongia, M.T. and P.N. Ireland (2016). "Money and Output: Friedman and Schwartz Revisited.” Journal of Money, Credit and Banking 48(6): 1223-1266.

Campbell, J. Y. and J. H. Cochrane (1999). "By Force of Habit: a Consumption-Based Explanation of Aggregate Stock Market Behavior," Journal of Political Economy 107: 205-251.

Cherchye, L., T. Demuynck, B. D. Rock, and P. Hjerstrand (2015), “Revealed Preference Tests for Weak Separability: An Integer Programming Approach," Journal of Econometrics 186(1): 129-141.

Cochrane, J. H. (2000). Asset Pricing, Princeton University Press, Princeton, NJ.

Divisia, F. (1925 and 1926). "L'IndiceMonétaire et la Théorie de la Monniae". Revue d'ÉconomiePolitique 39: 842-61, 980-1008 and 1121-51; and 40: 49-87. 
Feenstra, R. C. (1986). "Functional Equivalence Between Liquidity Costs and the Utility of Money," Journal of Monetary Economics, March, 271-291.

Fischer, S. (1974). "Money and the Production Function," Economic Inquiry 12, pp. 517-33.

Hjertstrand, P, J. L. Swofford, and G. Whitney (2016). "Revealed Preference Tests of Utility Maximization and Weak Separability of Consumption, Leisure and Money with Incomplete Adjustment, Journal of Money, Credit, and Banking, forthcoming.

Ingersoll, J. E. (1987). Theory of Financial Decision Making, Rowman and Littlefield, Totowa, NJ.

Kocherlakota, N. (1996). “The Equity Premium: It's Still a Puzzle," Journal of Economic Literature 34: 43-71.

Lucas, R. E. (1978). “Asset Prices in an Exchange Economy,” Econometrica 46: 14291445.

Marshall, D (1997). “Comments on CAPM Risk Adjustment for Exact Aggregation over Financial Assets, Macroeconomic Dynamics 1: 513-523.

Mehra, R. and E. C. Prescott (1985). "The Equity Premium: A Puzzle," Journal of Monetary Economics 15, 145-61.

Phlips, L. and F. Spinnewyn (1982). "Rationality versus Myopia in Dynamic Demand Systems," in R. L. Basmann and G. F. Rhodes (eds.), Advances in Econometrics, JAI Press, pp. 3-33.

Poterba, J.M. and J.J. Rotemberg (1987). "Money in the Utility Function: An Empirical Implementation," Chapter 10 in W.A. Barnett and K.J. Singleton (eds) New Approaches to Monetary Economics. Cambridge: Cambridge University Press: 219-40.

Quirk, J. and R. Saposnik (1968). Introduction to General Equilibrium Theory and Welfare Economics. New York: McGraw-Hill.

Rubinstein, M. (1976). "The Valuation of Uncertain Income Streams and the Pricing of Options," Bell Journal of Economics 7: 407-425.

Samuelson, P. (1948). Foundations of Economic Analysis, Harvard University Press, Cambridge, Mass.

Serletis, A. and P. Gogas (2014)."Divisia Monetary Aggregates, the Great Ratios, and Classical Money Demand Functions," Journal of Money, Credit and Banking 46(1): $229-41$. 
Serletis, A. and S. Rahman (2013). "The Case for Divisia Money Targeting," Macroeconomic Dynamics 17: 1638-1658.

Stein, C. (1973). "Estimation of the Mean of a Multivariate Normal Distribution," Proceedings of the Prague Symposium on Asymptotic Statistics, September.

Telyukova, I. and R. Wright (2008). "A Model of Money and Credit, with Application to the Credit Card Debt Puzzle," Review of Economic Studies 75: 629-647. 


\section{APPENDICES}

(I) Derivation of Euler Equations for Credit Card Services, Equation (12):

The following are the Euler equations provided in the paper as equations (11), (12), and (13):

$$
\begin{aligned}
& \frac{\partial V}{\partial m_{i t}}-\rho E_{t}\left[\left(R_{t}^{*}-r_{i t}^{*}\right) \frac{\partial V}{\partial X_{t+1}}\right]=0, \\
& \frac{\partial V}{\partial c_{j t}}-\rho E_{t}\left[\left(e_{j t}^{*}-R_{t}^{*}\right) \frac{\partial V}{\partial X_{t+1}}\right]=0, \\
& \frac{\partial V}{\partial X_{t}}-\rho E_{t}\left[\left(1+R_{t}^{*}\right) \frac{\partial V}{\partial X_{t+1}}\right]=0 .
\end{aligned}
$$

for all $s \geq t, i=1, \ldots, n$, and $j=1, \ldots, k$, where $\rho=1 /(1+\xi)$ and where $p_{s}^{*}$ is the exact price aggregate that is dual to the consumer goods quantity aggregate $X_{S}$.

Equation (A.1) was derived in Barnett (1995, Sec 2.3) using Bellman's method. An alternative approach to that derivation using calculus of variations was provided by Poterba and Rotemberg (1987). Equation (A.2) follows by the same approach to derivation, using either Bellman's method or calculus of variations. We are not providing the lengthy derivation of (A.2) in this appendix, since the steps in the Bellman method approach for this class of models are provided in detail in Barnett and Serletis (2000, pp. 201-204).

\section{(II) Proof of Theorem 1}

Theorem 1 (a). The risk adjusted real user cost of the services of monetary asset $i$ under risk is $p_{i t}^{m}=\pi_{i t}+\psi_{i t}$, where

$$
\pi_{i t}=\frac{E_{t} R_{t}^{*}-E_{t} r_{i t}^{*}}{1+E_{t} R_{t}^{*}}
$$


and

$$
\psi_{i t}=\rho\left(1-\pi_{i t}\right) \frac{\operatorname{Cov}\left(R_{t}^{*}, \frac{\partial V}{\partial X_{t+1}}\right)}{\frac{\partial V}{\partial X_{t}}}-\rho \frac{\operatorname{Cov}\left(r_{i t}^{*}, \frac{\partial V}{\partial X_{t+1}}\right)}{\frac{\partial V}{\partial X_{t}}} .
$$

(b). The risk adjusted real user cost of the services of credit card type $j$ under risk is $\wp_{j t}^{c}=\tilde{\pi}_{j t}+\tilde{\psi}_{j t}$, where

$$
\tilde{\pi}_{j t}=\frac{E_{t} e_{j t}^{*}-E_{t} R_{t}^{*}}{1+E_{t} R_{t}^{*}}
$$

and

$$
\tilde{\psi}_{j t}=\rho \frac{\operatorname{Cov}\left(e_{j t}^{*}, \frac{\partial V}{\partial X_{t+1}}\right)}{\frac{\partial V}{\partial X_{t}}}-\rho\left(1+\tilde{\pi}_{j t}\right) \frac{\operatorname{Cov}\left(R_{t}^{*}, \frac{\partial V}{\partial X_{t+1}}\right)}{\frac{\partial V}{\partial X_{t}}} .
$$

Proof. For the analogous proof in the case of monetary assets only, relevant to part (a), see Barnett, Liu, and Jensen (1997), Barnett and Serletis (2000, ch. 12), or Barnett (2012, Appendix D). We provide the proof of part (b) for the extended case including credit. There are two approaches to proving this important theorem, the direct approach and the indirect approach. We provide both approaches, beginning with the indirect approach.

By definition (1) in the paper, we have for the credit card services user cost price

$$
\wp_{j t}^{c}=\frac{\partial V}{\partial c_{j t}} / \frac{\partial V}{\partial X_{t}}
$$


Defining $\tilde{\psi}_{j t}$ to be $\tilde{\psi}_{j t}=\wp_{j t}^{c}-\tilde{\pi}_{j t}$, it follows that

$$
\frac{\partial V}{\partial c_{j t}}=\left(\tilde{\pi}_{j t}+\tilde{\psi}_{j t}\right) \frac{\partial V}{\partial X_{t}}
$$

Substituting equations (A.2) and (A.3) into this equation, we get

$$
\rho E_{t}\left[\left(e_{j t}^{*}-R_{t}^{*}\right) \frac{\partial V}{\partial X_{t+1}}\right]=\left(\tilde{\pi}_{j t}+\tilde{\psi}_{j t}\right) \rho E_{t}\left[\left(1+R_{t}^{*}\right) \frac{\partial V}{\partial X_{t+1}}\right] .
$$

Using the expectation of the product of correlated random variables, we have

$$
\begin{aligned}
& E_{t}\left(e_{j t}^{*}-R_{t}^{*}\right) E_{t}\left(\frac{\partial V}{\partial X_{t+1}}\right)+\operatorname{Cov}\left(e_{j t}^{*}-R_{t}^{*}, \frac{\partial V}{\partial X_{t+1}}\right) \\
& =\left\{\left[\frac{E_{t} e_{j t}^{*}-E_{t} R_{t}^{*}}{1+E_{t} R_{t}^{*}}\right]+\tilde{\psi}_{j t}\right\}\left\{E_{t}\left(1+R_{t}^{*}\right) E_{t}\left(\frac{\partial V}{\partial X_{t+1}}\right)+\operatorname{Cov}\left(R_{t}^{*}, \frac{\partial V}{\partial X_{t+1}}\right)\right\} .
\end{aligned}
$$

Multiplying $\left(1+E_{t} R_{t}^{*}\right)$ through on both sides of the equation, we get:

$$
\begin{aligned}
& \left(1+E_{t} R_{t}^{*}\right) E_{t}\left(e_{j t}^{*}-R_{t}^{*}\right) E_{t}\left(\frac{\partial V}{\partial X_{t+1}}\right)+\left(1+E_{t} R_{t}^{*}\right) \operatorname{Cov}\left(e_{j t}^{*}-R_{t}^{*}, \frac{\partial V}{\partial X_{t+1}}\right) \\
& =\left[E_{t}\left(e_{j t}^{*}-R_{t}^{*}\right)+\left(1+E_{t} R_{t}^{*}\right) \tilde{\psi}_{j t}\right]\left\{E_{t}\left(1+R_{t}^{*}\right) E_{t}\left(\frac{\partial V}{\partial X_{t+1}}\right)+\operatorname{Cov}\left(R_{t}^{*}, \frac{\partial V}{\partial X_{t+1}}\right)\right\} .
\end{aligned}
$$

Manipulating the algebra, we have

$$
\begin{aligned}
& E_{t}\left(e_{j t}^{*}-R_{t}^{*}\right) E_{t}\left(\frac{\partial V}{\partial X_{t+1}}\right)+\left(E_{t} R_{t}^{*}\right) E_{t}\left(e_{j t}^{*}-R_{t}^{*}\right) E_{t}\left(\frac{\partial V}{\partial X_{t+1}}\right)+\operatorname{Cov}\left(e_{j t}^{*}-R_{t}^{*}, \frac{\partial V}{\partial X_{t+1}}\right) \\
& +\left(E_{t} R_{t}^{*}\right) \operatorname{Cov}\left(e_{j t}^{*}-R_{t}^{*}, \frac{\partial V}{\partial X_{t+1}}\right) \\
& =\left[E_{t}\left(e_{j t}^{*}-R_{t}^{*}\right)+\left(1+E_{t} R_{t}^{*}\right) \tilde{\psi}_{j t}\right]\left\{E_{t}\left(\frac{\partial V}{\partial X_{t+1}}\right)+\left(E_{t} R_{t}^{*}\right) E_{t}\left(\frac{\partial V}{\partial X_{t+1}}\right)+\operatorname{Cov}\left(R_{t}^{*}, \frac{\partial V}{\partial X_{t+1}}\right)\right\},
\end{aligned}
$$


and hence

$$
\begin{aligned}
& E_{t}\left(e_{j t}^{*}-R_{t}^{*}\right) E_{t}\left(\frac{\partial V}{\partial X_{t+1}}\right)+\left(E_{t} R_{t}^{*}\right) E_{t}\left(e_{j t}^{*}-R_{t}^{*}\right) E_{t}\left(\frac{\partial V}{\partial X_{t+1}}\right)+\operatorname{Cov}\left(e_{j t}^{*}-R_{t}^{*}, \frac{\partial V}{\partial X_{t+1}}\right) \\
& +\left(E_{t} R_{t}^{*}\right) \operatorname{Cov}\left(e_{j t}^{*}-R_{t}^{*}, \frac{\partial V}{\partial X_{t+1}}\right) \\
& =E_{t}\left(e_{j t}^{*}-R_{t}^{*}\right) E_{t}\left(\frac{\partial V}{\partial X_{t+1}}\right)+E_{t}\left(e_{j t}^{*}-R_{t}^{*}\right)\left(E_{t} R_{t}^{*}\right)\left(E_{t}\left(\frac{\partial V}{\partial X_{t+1}}\right)\right)+E_{t}\left(e_{j t}^{*}-R_{t}^{*}\right) \operatorname{Cov}\left(R_{t}^{*}, \frac{\partial V}{\partial X_{t+1}}\right) \\
& +\left(1+E_{t} R_{t}^{*}\right) \tilde{\psi}_{j t}\left\{E_{t}\left(\frac{\partial V}{\partial X_{t+1}}\right)+\left(E_{t} R_{t}^{*}\right)\left(E_{t}\left(\frac{\partial V}{\partial X_{t+1}}\right)\right)+\operatorname{Cov}\left(R_{t}^{*}, \frac{\partial V}{\partial X_{t+1}}\right)\right\} .
\end{aligned}
$$

Notice that by equation (A.3),

$$
\begin{aligned}
\frac{\partial V}{\partial X_{t}} & =\rho E_{t}\left[\left(1+R_{t}^{*}\right) \frac{\partial V}{\partial X_{t+1}}\right] \\
& =\rho\left\{E_{t}\left(\frac{\partial V}{\partial X_{t+1}}\right)+\left(E_{t} R_{t}^{*}\right)\left(E_{t}\left(\frac{\partial V}{\partial X_{t+1}}\right)\right)+\operatorname{Cov}\left(R_{t}^{*}, \frac{\partial V}{\partial X_{t+1}}\right)\right\} .
\end{aligned}
$$

Substituting this back into the prior equation, we have

$$
\begin{aligned}
& E_{t}\left(e_{j t}^{*}-R_{t}^{*}\right) E_{t}\left(\frac{\partial V}{\partial X_{t+1}}\right)+\left(E_{t} R_{t}^{*}\right) E_{t}\left(e_{j t}^{*}-R_{t}^{*}\right) E_{t}\left(\frac{\partial V}{\partial X_{t+1}}\right)+\operatorname{Cov}\left(e_{j t}^{*}-R_{t}^{*}, \frac{\partial V}{\partial X_{t+1}}\right) \\
& +\left(E_{t} R_{t}^{*}\right) \operatorname{Cov}\left(e_{j t}^{*}-R_{t}^{*}, \frac{\partial V}{\partial X_{t+1}}\right) \\
& =E_{t}\left(e_{j t}^{*}-R_{t}^{*}\right) E_{t}\left(\frac{\partial V}{\partial X_{t+1}}\right)+E_{t}\left(e_{j t}^{*}-R_{t}^{*}\right)\left(E_{t} R_{t}^{*}\right)\left(E_{t}\left(\frac{\partial V}{\partial X_{t+1}}\right)\right)+E_{t}\left(e_{j t}^{*}-R_{t}^{*}\right) \operatorname{Cov}\left(R_{t}^{*}, \frac{\partial V}{\partial X_{t+1}}\right) \\
& +\left(1+E_{t} R_{t}^{*}\right) \tilde{\psi}_{j t}\left(\frac{1}{\rho} \frac{\partial V}{\partial X_{t}}\right) .
\end{aligned}
$$

Simplifying the equation, we get 


$$
\begin{aligned}
& \operatorname{Cov}\left(e_{j t}^{*}-R_{t}^{*}, \frac{\partial V}{\partial X_{t+1}}\right)+\left(E_{t} R_{t}^{*}\right) \operatorname{Cov}\left(e_{j t}^{*}-R_{t}^{*}, \frac{\partial V}{\partial X_{t+1}}\right) \\
& =E_{t}\left(e_{j t}^{*}-R_{t}^{*}\right) \operatorname{Cov}\left(R_{t}^{*}, \frac{\partial V}{\partial X_{t+1}}\right)+\left(1+E_{t} R_{t}^{*}\right) \tilde{\psi}_{j t}\left(\frac{1}{\rho} \frac{\partial V}{\partial X_{t}}\right) .
\end{aligned}
$$

Recall that by equation (A.6),

$$
\tilde{\pi}_{j t}=\frac{E_{t} e_{j t}^{*}-E_{t} R_{t}^{*}}{1+E_{t} R_{t}^{*}}
$$

Substituting this equation back into the prior equation, we have

$$
\begin{aligned}
& \operatorname{Cov}\left(e_{j t}^{*}-R_{t}^{*}, \frac{\partial V}{\partial X_{t+1}}\right)+\left(E_{t} R_{t}^{*}\right) \operatorname{Cov}\left(e_{j t}^{*}-R_{t}^{*}, \frac{\partial V}{\partial X_{t+1}}\right) \\
& =\tilde{\pi}_{j t}\left(1+E_{t} R_{t}^{*}\right) \operatorname{Cov}\left(R_{t}^{*}, \frac{\partial V}{\partial X_{t+1}}\right)+\left(1+E_{t} R_{t}^{*}\right) \tilde{\psi}_{j t}\left(\frac{1}{\rho} \frac{\partial V}{\partial X_{t}}\right) .
\end{aligned}
$$

Rearranging the equation, we have

$$
\left(1+E_{t} R_{t}^{*}\right) \operatorname{Cov}\left(e_{j t}^{*}-R_{t}^{*}, \frac{\partial V}{\partial X_{t+1}}\right)=\tilde{\pi}_{j t}\left(1+E_{t} R_{t}^{*}\right) \operatorname{Cov}\left(R_{t}^{*}, \frac{\partial V}{\partial X_{t+1}}\right)+\left(1+E_{t} R_{t}^{*}\right) \tilde{\psi}_{j t}\left(\frac{1}{\rho} \frac{\partial V}{\partial X_{t}}\right),
$$

so that

$$
\operatorname{Cov}\left(e_{j t}^{*}-R_{t}^{*}, \frac{\partial V}{\partial X_{t+1}}\right)=\tilde{\pi}_{j t} \operatorname{Cov}\left(R_{t}^{*}, \frac{\partial V}{\partial X_{t+1}}\right)+\tilde{\psi}_{j t}\left(\frac{1}{\rho} \frac{\partial V}{\partial X_{t}}\right)
$$

Hence, it follows that 


$$
\begin{aligned}
\tilde{\psi}_{j t} & =\rho \frac{\operatorname{Cov}\left(e_{j t}^{*}-R_{t}^{*}, \frac{\partial V}{\partial X_{t+1}}\right)}{\frac{\partial V}{\partial X_{t}}}-\rho \tilde{\pi}_{j t} \frac{\operatorname{Cov}\left(R_{t}^{*}, \frac{\partial V}{\partial X_{t+1}}\right)}{\frac{\partial V}{\partial X_{t}}} \\
& =\rho \frac{\operatorname{Cov}\left(e_{j t}^{*}, \frac{\partial V}{\partial X_{t+1}}\right)}{\frac{\partial V}{\partial X_{t}}}-\rho \frac{\operatorname{Cov}\left(R_{t}^{*}, \frac{\partial V}{\partial X_{t+1}}\right)}{\frac{\partial V}{\partial X_{t}}}-\rho \tilde{\pi}_{j t} \frac{\operatorname{Cov}\left(R_{t}^{*}, \frac{\partial V}{\partial X_{t+1}}\right)}{\frac{\partial V}{\partial X_{t}}} \\
& =\rho \frac{\operatorname{Cov}\left(e_{j t}^{*}, \frac{\partial V}{\partial X_{t+1}}\right)}{\frac{\partial V}{\partial X_{t}}}-\rho\left(1+\tilde{\pi}_{j t}\right) \frac{\operatorname{Cov}\left(R_{t}^{*}, \frac{\partial V}{\partial X_{t+1}}\right)}{\frac{\partial V}{\partial X_{t}}} .
\end{aligned}
$$

The alternative direct approach to proof is the following.

By equation (A.3), we have

$$
\begin{aligned}
\frac{\partial V}{\partial X_{t}} & =\rho E_{t}\left[\left(1+R_{t}^{*}\right) \frac{\partial V}{\partial X_{t+1}}\right] \\
& =\rho\left(1+E_{t} R_{t}^{*}\right)\left(E_{t}\left(\frac{\partial V}{\partial X_{t+1}}\right)\right)+\rho \operatorname{Cov}\left(R_{t}^{*}, \frac{\partial V}{\partial X_{t+1}}\right) .
\end{aligned}
$$

Rearranging, we get

$$
\rho\left(1+E_{t} R_{t}^{*}\right)\left(E_{t}\left(\frac{\partial V}{\partial X_{t+1}}\right)\right)=\frac{\partial V}{\partial X_{t}}-\rho \operatorname{Cov}\left(R_{t}^{*}, \frac{\partial V}{\partial X_{t+1}}\right),
$$

and hence

$$
\rho E_{t}\left(\frac{\partial V}{\partial X_{t+1}}\right)=\frac{1}{1+E_{t} R_{t}^{*}}\left[\frac{\partial V}{\partial X_{t}}-\rho \operatorname{Cov}\left(R_{t}^{*}, \frac{\partial V}{\partial X_{t+1}}\right)\right] .
$$

But from (A.12), we have 


$$
\frac{\partial V}{\partial c_{j t}}=\rho E_{t}\left[\left(e_{j t}-R_{t}^{*}\right) \frac{\partial V}{\partial X_{t+1}}\right]
$$

From the expectation of the correlated product, we then have

$$
\frac{\partial V}{\partial c_{j t}}=\rho E_{t}\left(e_{j t}-R_{t}^{*}\right) E_{t}\left(\frac{\partial V}{\partial X_{t+1}}\right)+\rho \operatorname{Cov}\left[\left(e_{j t}-R_{t}^{*}\right), \frac{\partial V}{\partial X_{t+1}}\right],
$$

so that

$$
\frac{\partial V}{\partial c_{j t}}=\rho E_{t}\left(e_{j t}-R_{t}^{*}\right) E_{t}\left(\frac{\partial V}{\partial X_{t+1}}\right)+\rho \operatorname{Cov}\left(e_{j t}, \frac{\partial V}{\partial X_{t+1}}\right)-\rho \operatorname{Cov}\left(R_{t}^{*}, \frac{\partial V}{\partial X_{t+1}}\right) .
$$

Now substitute equation (A.9) into equation (A.10), to acquire

$$
\begin{aligned}
& \frac{\partial V}{\partial c_{j t}}=\frac{E_{t}\left(e_{j t}-R_{t}^{*}\right)}{1+E_{t} R_{t}^{*}}\left[\frac{\partial V}{\partial X_{t}}-\rho \operatorname{Cov}\left(R_{t}^{*}, \frac{\partial V}{\partial X_{t+1}}\right)\right]+\rho \operatorname{Cov}\left(e_{j t}, \frac{\partial V}{\partial X_{t+1}}\right)-\rho \operatorname{Cov}\left(R_{t}^{*}, \frac{\partial V}{\partial X_{t+1}}\right) \\
& =\tilde{\pi}_{j t}\left[\frac{\partial V}{\partial X_{t}}-\rho \operatorname{Cov}\left(R_{t}^{*}, \frac{\partial V}{\partial X_{t+1}}\right)\right]+\rho \operatorname{Cov}\left(e_{j t}, \frac{\partial V}{\partial X_{t+1}}\right)-\rho \operatorname{Cov}\left(R_{t}^{*}, \frac{\partial V}{\partial X_{t+1}}\right) .
\end{aligned}
$$

Multiplying and dividing the right side by $\frac{\partial V}{\partial X_{t}}$, we get 


$$
\begin{aligned}
& \frac{\partial V}{\partial c_{j t}}=\frac{\partial V}{\partial X_{t}}\left\{\tilde{\pi}_{j t}-\rho \tilde{\pi}_{j t} \frac{\operatorname{Cov}\left(R_{t}^{*}, \frac{\partial V}{\partial X_{t+1}}\right)}{\frac{\partial V}{\partial X_{t}}}+\rho \frac{\operatorname{Cov}\left(e_{j t}, \frac{\partial V}{\partial X_{t+1}}\right)}{\frac{\partial V}{\partial X_{t}}}-\rho \frac{\operatorname{Cov}\left(R_{t}^{*}, \frac{\partial V}{\partial X_{t+1}}\right)}{\frac{\partial V}{\partial X_{t}}}\right\} \\
& =\frac{\partial V}{\partial X_{t}}\left\{\tilde{\pi}_{j t}+\rho \frac{\operatorname{Cov}\left(e_{j t}, \frac{\partial V}{\partial X_{t+1}}\right)}{\frac{\partial V}{\partial X_{t}}}-\rho\left(1+\tilde{\pi}_{j t}\right) \frac{\operatorname{Cov}\left(R_{t}^{*}, \frac{\partial V}{\partial X_{t+1}}\right)}{\frac{\partial V}{\partial X_{t}}}\right\} .
\end{aligned}
$$

Define $\tilde{\psi}_{j t}$ by

$$
\tilde{\psi}_{j t}=\rho \frac{\operatorname{Cov}\left(e_{j t}, \frac{\partial V}{\partial X_{t+1}}\right)}{\frac{\partial V}{\partial X_{t}}}-\rho\left(1+\tilde{\pi}_{j t}\right) \frac{\operatorname{Cov}\left(R_{t}^{*}, \frac{\partial V}{\partial X_{t+1}}\right)}{\frac{\partial V}{\partial X_{t}}} .
$$

Then we have

$$
\frac{\frac{\partial V}{\partial c_{j t}}}{\frac{\partial V}{\partial X_{t}}}=\tilde{\pi}_{j t}+\tilde{\psi}_{j t},
$$

so that

$$
\wp_{j t}^{c}=\tilde{\pi}_{j t}+\tilde{\psi}_{j t} .
$$

\section{(III) Proof of Lemma 2:}

Assumption 1. Let $V$ have the form 
$V\left(\mathbf{m}_{t}, \mathbf{c}_{t}, X_{t}\right)=F\left[\mathcal{M}\left(\mathbf{m}_{t}, \mathbf{c}_{t}\right), X_{t}\right]=A\left[\mathcal{M}\left(\mathbf{m}_{t}, \mathbf{c}_{t}\right)\right] X_{t}-\frac{1}{2} B\left[\mathcal{M}\left(\mathbf{m}_{t}, \mathbf{c}_{t}\right)\right] X_{t}^{2}$,

Where $A$ is a positive, increasing, concave function and $B$ is a nonnegative, decreasing, convex function.

Assumption 2. Let $\left(r_{i t}^{*}, e_{j t}^{*}, X_{t+1}\right)$ be a trivariate Gaussian process for each asset $i=$ $1, \ldots, n$, and credit card service, $j=1, \ldots, k$.

Assumption 3. The benchmark rate process is deterministic or already riskadjusted, so that $R_{t}^{*}$ is the risk-free rate.

Under this assumption, it follows that

$$
\operatorname{Cov}\left(R_{t}^{*}, \frac{\partial V}{\partial X_{t+1}}\right)=0
$$

Define $H_{t+1}=H\left(\mathcal{M}_{t+1}, X_{t+1}\right)$ to be the well-known Arrow-Pratt measure of absolute risk aversion,

$$
H\left(\mathcal{M}_{t+1}, X_{t+1}\right)=-\frac{E_{t}\left[V^{\prime \prime}\right]}{E_{t}\left[V^{\prime}\right]},
$$

Where $V^{\prime}=\partial V\left(\boldsymbol{m}_{t+1}^{a}, X_{t+1}\right) / \partial X_{t+1}$ and $V^{\prime \prime}=\partial^{2} V\left(\boldsymbol{m}_{t+1}^{a}, X_{t+1}\right) / \partial X_{t+1}^{2}$.

Lemma 2. Under Assumption 3 and either Assumption 1 or Assumption 2, the usercost risk adjustments, $\psi_{i t}$ and $\tilde{\psi}_{j t}$, defined by (A.5) and (A.7), reduce to

$$
\psi_{i t}=\frac{1}{1+R_{t}^{*}} H_{t+1} \operatorname{cov}\left(r_{i t}^{*}, X_{t+1}\right)
$$


and

$$
\tilde{\psi}_{j t}=-\frac{1}{1+R_{t}^{*}} H_{t+1} \operatorname{cov}\left(e_{j t}^{*}, X_{t+1}\right) .
$$

Proof. For the analogous proof in the case of monetary assets only, see Barnett, Liu, and Jensen (1997), Barnett and Serletis (2000, ch. 12), or Barnett (2012, Appendix D). We provide the proof of equation (A.14) for the extended case including credit.

Under Assumption 3, the benchmark asset is risk-free, so that

$$
\operatorname{Cov}\left(R_{t}^{*}, \frac{\partial V}{\partial X_{t+1}}\right)=0 .
$$

By equation (A.7),

$$
\begin{aligned}
\tilde{\psi}_{j t} & =\rho \frac{\operatorname{Cov}\left(e_{j t}^{*}, \frac{\partial V}{\partial X_{t+1}}\right)}{\frac{\partial V}{\partial X_{t}}}-\rho\left(1+\tilde{\pi}_{j t}\right) \frac{\operatorname{Cov}\left(R_{t}^{*}, \frac{\partial V}{\partial X_{t+1}}\right)}{\frac{\partial V}{\partial X_{t}}} \\
& =\rho \frac{\operatorname{Cov}\left(e_{j t}^{*}, \frac{\partial V}{\partial X_{t+1}}\right)}{\frac{\partial V}{\partial X_{t}}} .
\end{aligned}
$$

But by equation (A.3),

$$
\frac{\partial V}{\partial X_{t}}=\rho E_{t}\left[\left(1+R_{t}^{*}\right) \frac{\partial V}{\partial X_{t+1}}\right],
$$

So

$$
\tilde{\psi}_{j t}=\rho \frac{\operatorname{Cov}\left(e_{j t}^{*}, \frac{\partial V}{\partial X_{t+1}}\right)}{\rho\left(1+R_{t}^{*}\right) E_{t}\left(\frac{\partial V}{\partial X_{t+1}}\right)}
$$




$$
=\frac{\operatorname{Cov}\left(e_{j t}^{*}, \frac{\partial V}{\partial X_{t+1}}\right)}{\left(1+R_{t}^{*}\right) E_{t}\left(\frac{\partial V}{\partial X_{t+1}}\right)} .
$$

Under Assumption 1,

$$
\frac{\partial V}{\partial X_{t}}=A\left[\mathcal{M}\left(\mathbf{m}_{t}, \mathbf{c}_{t}\right)\right]-B\left[\mathcal{M}\left(\mathbf{m}_{t}, \mathbf{c}_{t}\right)\right] X_{t}
$$

Hence,

$$
\frac{\partial^{2} V}{\partial X_{t}^{2}}=-B\left[\mathcal{M}\left(\mathbf{m}_{t}, \mathbf{c}_{t}\right)\right]
$$

Shifting one period forward, those two equations become

$$
\frac{\partial V}{\partial X_{t+1}}=V^{\prime}=A-B X_{t+1}
$$

and

$$
\frac{\partial^{2} V}{\partial X_{t}^{2}}=V^{\prime \prime}=-B
$$

Substituting into equation (A.15), we get

$$
\begin{aligned}
\tilde{\psi}_{j t} & =\frac{\operatorname{Cov}\left(e_{j t}^{*}, A-B X_{t+1}\right)}{\left(1+R_{t}^{*}\right) E_{t}\left(\frac{\partial V}{\partial X_{t+1}}\right)} \\
& =\frac{-B}{1+R_{t}^{*}} \frac{\operatorname{Cov}\left(e_{j t}^{*}, X_{t+1}\right)}{E_{t}\left(V^{\prime}\right)} \\
& =\frac{1}{1+R_{t}^{*}} \frac{E\left(V^{\prime \prime}\right)}{E_{t}\left(V^{\prime}\right)} \operatorname{Cov}\left(e_{j t}^{*}, X_{t+1}\right) \\
& =-\frac{1}{1+R_{t}^{*}} H_{t+1} \operatorname{Cov}\left(e_{j t}^{*}, X_{t+1}\right) .
\end{aligned}
$$


Alternatively, consider Assumption 2. We then can use Stein's lemma, which says the following. ${ }^{11}$ Suppose $(X, Y)$ are multivariate normal. Then

$$
\operatorname{Cov}(g(X), Y)=E\left(g^{\prime}(X)\right) \operatorname{Cov}(X, Y) .
$$

In that formula, let $g(X)=\frac{\partial V}{\partial X_{t+1}}, X=X_{t+1}$, and $Y=e_{j t}^{*}$. Then from Stein's lemma, we have

$$
\operatorname{Cov}\left(e_{j t}^{*}, \frac{\partial V}{\partial X_{t+1}}\right)=E_{t}\left(\frac{\partial^{2} V}{\partial X_{t+1}^{2}}\right) \operatorname{Cov}\left(X_{t+1}, e_{j t}^{*}\right) .
$$

Substituting into (A.15), we get

$$
\tilde{\psi}_{j t}=\frac{E_{t}\left(\frac{\partial^{2} V}{\partial X_{t+1}^{2}}\right) \operatorname{Cov}\left(X_{t+1}, e_{j t}^{*}\right)}{\left(1+R_{t}^{*}\right) E_{t}\left(\frac{\partial V}{\partial X_{t+1}}\right)} .
$$

Using the definitions of $V^{\prime}, V^{\prime \prime}$, and $H_{t+1}$, we have

$$
\tilde{\psi}_{j t}=-\frac{1}{1+R_{t}^{*}} H_{t+1} \operatorname{Cov}\left(e_{j t}^{*}, X_{t+1}\right)
$$

\section{(IV) Proof of Theorem 3:}

Theorem 3. Let $\hat{H}_{t}=H_{t+1} X_{t}$. Under the assumptions of Lemma 2, we have the following for each asset $i=1, \ldots, n$, and credit card service, $j=1, \ldots, k$,

$$
\wp_{i t}^{m}=\frac{E_{t} R_{t}^{*}-\left(E_{t} r_{i t}^{*}-\phi_{i t}\right)}{1+E_{t} R_{t}^{*}}
$$

${ }^{11}$ For Stein's lemma, see Stein (1973), Ingersoll (1987, p. 13, eq. 62) or Rubinstein (1976). 
where

$$
\phi_{i t}=\hat{H}_{t} \operatorname{Cov}\left(r_{i t}^{*}, \frac{X_{t+1}}{X_{t}}\right)
$$

and

$$
\wp_{j t}^{c}=\frac{\left(E_{t} e_{j t}^{*}-\tilde{\phi}_{j t}\right)-E_{t} R_{t}^{*}}{1+E_{t} R_{t}^{*}}
$$

where

$$
\tilde{\phi}_{j t}=\hat{H}_{t} \operatorname{Cov}\left(e_{j t}^{*}, \frac{X_{t+1}}{X_{t}}\right) .
$$

Proof. For the proof in the case of monetary assets only, relevant to equations (A.16) and (A.17), see Barnett, Liu, and Jensen (1997), Barnett and Serletis (2000, ch. 12), or Barnett (2012, Appendix D). We here provide the proof of equations (A.18) and (A.19) for the extended case including credit.

From part b of Theorem 1,

$$
\wp_{j t}^{c}=\frac{E_{t} e_{j t}^{*}-E_{t} R_{t}^{*}}{1+E_{t} R_{t}}+\tilde{\psi}_{j t} .
$$

Letting $\hat{H}_{t}=H_{t+1} X_{t}$. and using Lemma 2, we get 


$$
\begin{aligned}
\wp_{j t}^{c} & =\frac{E_{t} e_{j t}^{*}-E_{t} R_{t}^{*}}{1+E_{t} R_{t}}-\frac{H_{t+1} \operatorname{Cov}\left(e_{j t}^{*}, X_{t+1}\right)}{1+E_{t} R_{t}^{*}} \\
& =\frac{E_{t} e_{j t}^{*}-E_{t} R_{t}^{*}}{1+E_{t} R_{t}}-\frac{H_{t+1} X_{t} \operatorname{Cov}\left(e_{j t}^{*}, \frac{X_{t+1}}{X_{t}}\right)}{1+E_{t} R_{t}^{*}} \\
& =\frac{E_{t} e_{j t}^{*}-E_{t} R_{t}^{*}}{1+E_{t} R_{t}}-\frac{\hat{H}_{t} \operatorname{Cov}\left(e_{j t}^{*}, \frac{X_{t+1}}{X_{t}}\right)}{1+E_{t} R_{t}^{*}} .
\end{aligned}
$$

Define $\tilde{\phi}_{j, t}=\hat{H}_{t} \operatorname{Cov}\left(e_{j t}^{*}, \frac{X_{t+1}}{X_{t}}\right)$ to get

$$
\begin{aligned}
\wp_{j t}^{c} & =\frac{E_{t} e_{j t}^{*}-E_{t} R_{t}^{*}}{1+E_{t} R_{t}}-\frac{\tilde{\phi}_{j t}}{1+E_{t} R_{t}^{*}} \\
& =\frac{\left(E_{t} e_{j t}^{*}-\tilde{\phi}_{j t}\right)-E_{t} R_{t}^{*}}{1+E_{t} R_{t}^{*}} .
\end{aligned}
$$

